EPISODIC RIFTING AND VOLCANISM AT KRAFLA IN NORTH ICELAND: GROWTH OF LARGE GROUND FISSURES ALONG THE PLATE BOUNDARY

\title{
Egil1 Hauksson
}

\section{Lamont-Doherty Geological Observatory of Columbia University} Palisades, New York 10964

\begin{abstract}
The rifting of the plate boundary in north Iceland forms new ground fissures and reactivates old ones. Continuous growth of fissures is observed in the crust above a magma chamber beneath the Krafla caldera as it responds to changes in subterranean magma pressure. Rapid episodes of fissure formation and reactivation are observed in conjunction with magma intrusions at depth along the rift zone that constitutes the plate boundary between the North American and Eurasian plates. The Krafla caldera contains several fissures that open during periods of uplift lasting 100 to 300 days and that close incompletely in subsidence episodes lasting several hours to 3 weeks. The average rate of opening differs from one period to another, ranging from 0.1 to $0.5 \mathrm{~mm} / \mathrm{d}$. Fissure closing and average closing rates also vary from one subsidence episode to another, ranging from minimal values of 2.1 mm and $2.3 \mathrm{~mm} / \mathrm{d}$ to maximal values of $49 \mathrm{~nm}$ and $18 \mathrm{~mm} / \mathrm{d}$, respectively. During the two intrusion episodes of September 1977 and March 1980 the magma migrated toward the south with an average velocity 0.6 and $0.5 \mathrm{~m} / \mathrm{s}$, respectively. In the September 1977 episode some fissures in the rift zone widened with a rate greater than $190 \mathrm{~mm} / \mathrm{d}$, whereas during the March episode that probably resulted in a thinner intrusion the maximum widening rate was only 50 $\mathrm{mm} / \mathrm{d}$. The data suggest that the magnitude of a subsidence episode is determined at least partly by the available excess magma pressure in the chamber. To explain the extensive growth of open fissures and normal faulting in the rift zone, it is necessary to assume that in addition to the intrusion of the main central dike at depth, many small dikes are intruded at shallow depths (less than $1 \mathrm{~km}$ ).
\end{abstract}

\section{Introduction}

Since December 1975, the Krafla volcano and its associated fissure swarm in north Iceland have been the site of extensive rifting and volcanism. As the Eurasian and the North American plates are being rifted apart, swarms of macroscopic cracks or open fissures grow along the plate boundary (see Figure 1). The main purpose of this work is to document the evolution of these tectonic features and to relate them with possible subterranean movements of magma.

An at tempt to interpret in terms of plate tectonics the existence of open ground fissures in the rift zones in Iceland was made by Nakamura [1970]. He studied the azimuthal distribution of en echelon ground fissures in southwestern

Conyright 1983 by the American Geophysical Union.

Paper number 2B 1669 .

$0148-7227 / 83 / 002 B-1669 \$ 05.00$
Iceland and suggested that the fissures were pure extensional features rather than the surface features of a buried transcurrent fault. Reactivation of existing fissures below the Langalda dam in south Iceland was reported by Tomasson [1976]. When the reservoir was impounded, a fissure opened below the 10-m-high earth daro and extended at least 1 kn upstream. Tomasson suggested that the fissure opening was caused by an increase in the hydrostatic pressure within the fissure that may have finally exceeded the horizontal compressive stress and the tensile strength of the rock. Sigurdsson [1980] and Bjornsson et a1. [1979] presented measurements and eyewitness accounts of surface deformation including changes in displacement across fissures in the Krafla rift zone that were associated with uplift or subsidence of the caldera floor and subsurface movements of magma. For 1 month in 1976, Pelzer and Gerstenecker [1980] recorded the change in opening of one fissure located in the rift zone $50 \mathrm{~km}$ north of the Krafla caldera. They found an average extension of $5 \mu \mathrm{m} / \mathrm{d}$ and some step offsets of $50 \mathrm{\mu m}$. Since the duration of their monitoring was only 1 month, it is difficult to evaluate the significance of their observations.

The data presented here are continuous and cover a period of 4 years. The intention was to obtain a data set that would complement the less Frequent geodetic observations. Therefore, the timing of fissure events and the rate with which they occur are emphasized below. Further, an attempt is made to interpret the extensive fissuring in terms of a suite of dikes of varying size and depth.

\section{Observations and Experimental Procedures}

In July 1977 a total of 16 displacement meters were deployed to monitor possible changes in displacement across open ground fissures in the Krafla caldera and in the rift zone south of the caldera. These instruments have produced a 4-year-long record of displacement data from 14 different open ground fissures.

Instrumentation. A displacement meter (a)so often called a creep meter or an extensometer) measures the change in displacement or relative distance across faults or open ground fissures. A schematic illustration of the instrument and a typical installation is shown in Figure 2. The shaft of a $360^{\circ}$ continuous rotation potentiometer is caused to rotate when a fissure opens, thereby varying the current through a galvanometer recorder. The system is similar to that used to monitor creep on active faults in California [e.g., Duffie1d and Burford, 1973; Burford et al., 1978]. The total range is limited by a spring and a steel wire length to approximately $120 \mathrm{~mm}$, and the sensitivity is proportional to 


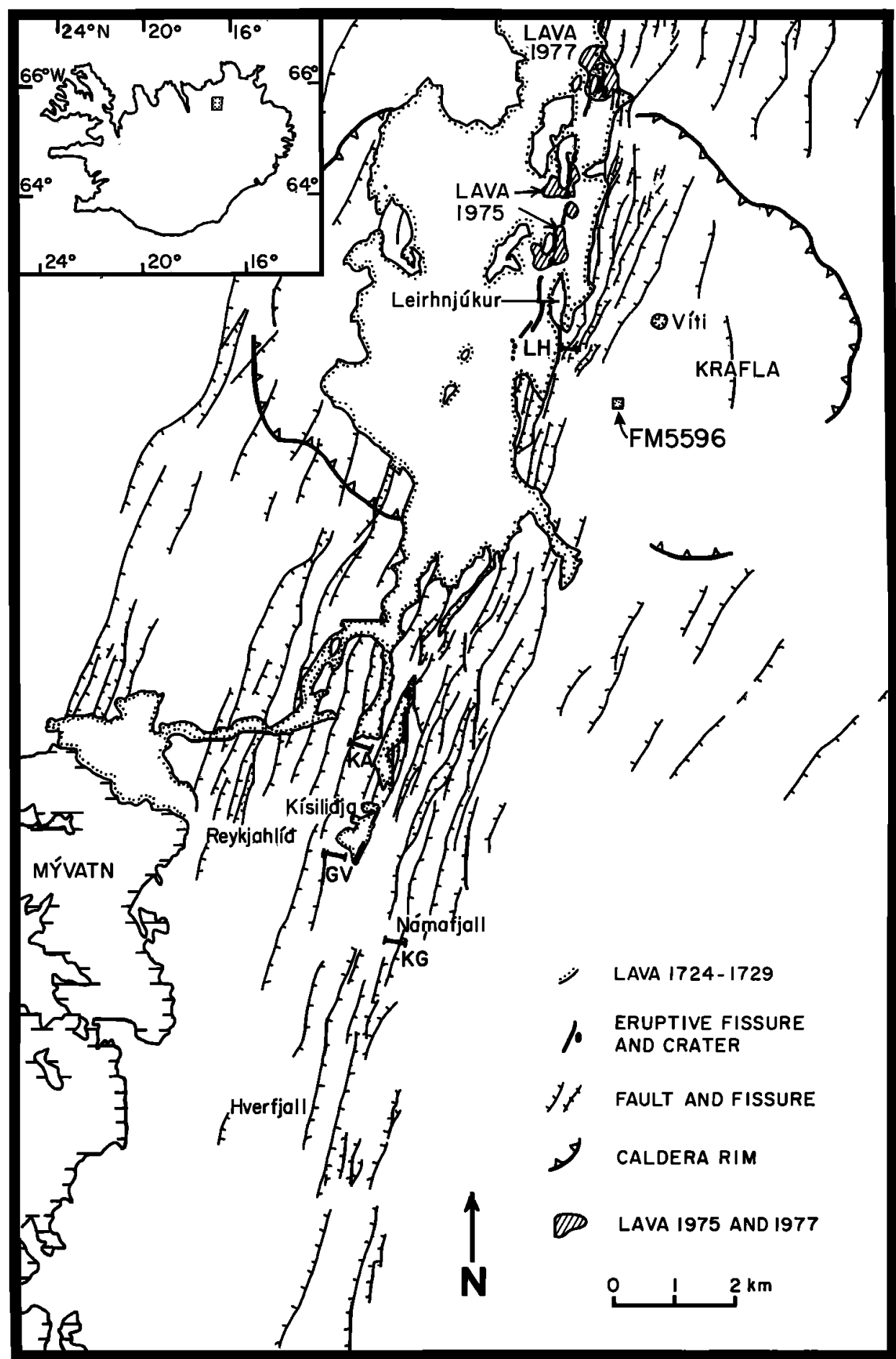

Fig. l. Krafla central volcano and associated fissure swarm, north Iceland, adapted from Saemundsson [1977, 1978]. C]usters of displacement meters are shown as LH, KA, GV, and KG. A map of the figure is shown in the upper left-hand corner.

the circumference of the shaft of the potentiometer $(10.7 \mathrm{~mm})$. On the 6-cm-wide chart of the recorder it is possible to resolve $0.1-\mathrm{mm}$ changes in fissure width.

Two-conductor, twisted-pair cables were used to transfer the signals from three or four closely spaced displacement meters to a central recording site. As many as four displacement meters were sampled sequentially for $7.5 \mathrm{~min}$ by each chart recorder. During each 7.5-min sampling period, data points were acquired every minute. The chart speed was approximately 40 $\mathrm{mm} / \mathrm{d}$ with daily time marks. This could be increased by a factor of 4 with 6-hour time marks on occasions when increased fissure activity appeared likely.

These simple instruments proved to be very reliable and are ideal for monitoring slow crack 


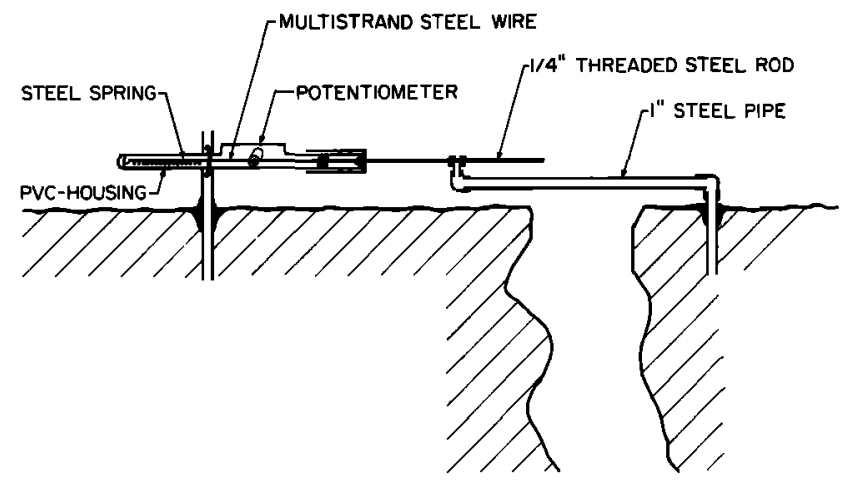

Fig. 2. A displacement meter installed across an open fissure. The l-in. steel pipe permits installation of the meter on one side of the fissure to avoid snow load damage. When the fissure walls move apart, the potentiometer is rotated by the pretensioned multistrand steel wire.

motion in the velocity range from $0.1 \mathrm{~mm} / \mathrm{yr}$ up to $10 \mathrm{~mm} / \mathrm{h}$. If the motion is more rapid, the recorder may loose count of the numbers of turns of the potentiometer. The temperature coefficient of the system is approximately $10^{-5} /{ }^{\circ} \mathrm{C}\left(0.1\right.$ man per $20^{\circ}$ in a $5-\mathrm{m}$ instrument). Thus, if the velocity is less than $0.1 \mathrm{~mm} / \mathrm{yr}$, changes in atmospheric temperature may contaminate the data. At one recording site (KG), one of the channels was devoted to recording the atmospheric temperature, and the average range of daily and annual temperature fluctuations was approximately $20^{\circ}$ and $15^{\circ} \mathrm{C}$, respectively.

Configuration of the array. The displacement meters were installed in four different clusters ( $\mathrm{LH}, \mathrm{KA}, \mathrm{GV}$, and $\mathrm{KG}$ ), forming an array that extends from the center of the caldera toward the south approximately $10 \mathrm{~km}$ (Figure 1). The siting of displacement meters within each of the clusters is shown in detail in Figure 3.

Initially, the LH cluster consisted of four displacement meters. The LH1 and LH2 are installed across the same fissure and monitor the opening and the shear displacement, respectively. The LH3 meter was crushed by rocks from a collapsing fissure wall during the September 1977 rifting episode. The LH4 meter repeatedly suffered extensive damage either during rifting episodes or from heavy snow loads during the winter munths. Therefore, no data were retrieved from LH3, and only small segments of data were produced by LH4. During the latter half of 1978 and first half of 1979 the data from the LH2 meter were not recorded because of problems with the electrical wiring to the recorder.

The KA, GV, and KG clusters monitor different en echelon segments of the rift zone. Some of the fissures moved too fast during september 1977, and no records of the movements could be retrieved (see, for example, KA4 and GV1 in Figure 6). The $\mathrm{KAl}$ and GVl meters were damaged and were not repaired until July 1978. Further, some of the 1978 and 1979 data from the GV cluster are missing because the recorder broke down. The data retrieval from the remaining instruments was close to $100 \%$.
Data reduction. The strip charts were retrieved from the recorders twice a year. Using a manually operated cursor and a digitizing table, digitized values, each representing approximately 1 hour of data, were punched onto computer cards. The raw digitized values were interpolated to obtain evenly spaced hourly values that were then stored in computer data files for plotting and further processing.

\section{Results}

\section{Fissures in the Caldera}

The general distribution of open fissures and normal faults that define the rift zone was mapped by Saemundsson [1977, 1978] (see also Figure 1). An open fissure in the caldera, labeled LH in Figure 1, was monitored using two displacement meters that measured the normal and shear components of motion. This fissure (which is referred to as $L 6$ by Bjornsson et a1. [1979] and Hauksson [1981]) was chosen for monitoring since it was observed to show variation in width during the early stages of rifting [Bjornsson et a1., 1979]. The fissure is located approximately $200 \mathrm{~m}$ east of the center of the rift axis, which strikes north $15^{\circ}$ east across the caldera. The fissure has a maximum opening of $5 \mathrm{~m}$ at its center where the displacement meter is located and the width tapers off away from the center, disappearing within several hundred meters in each direction.

The data recorded by the LHl displacement meter indicate that periods of fissure opening correspond to periods of land uplift (Figure 4), as was found also by Bjornsson et al. [1979].

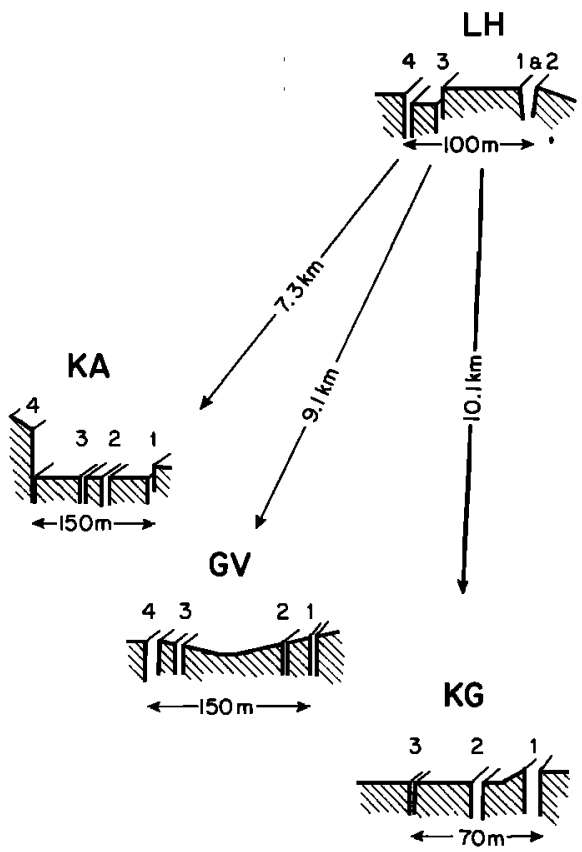

Fig. 3. A schematic illustration of fisures and blocks whose movements are monitored by the displacement meters. The average fissure width is approximately $0.3-0.5 \mathrm{~m}$. Note that only some of the fissures have a significant vertical throw. 
1977

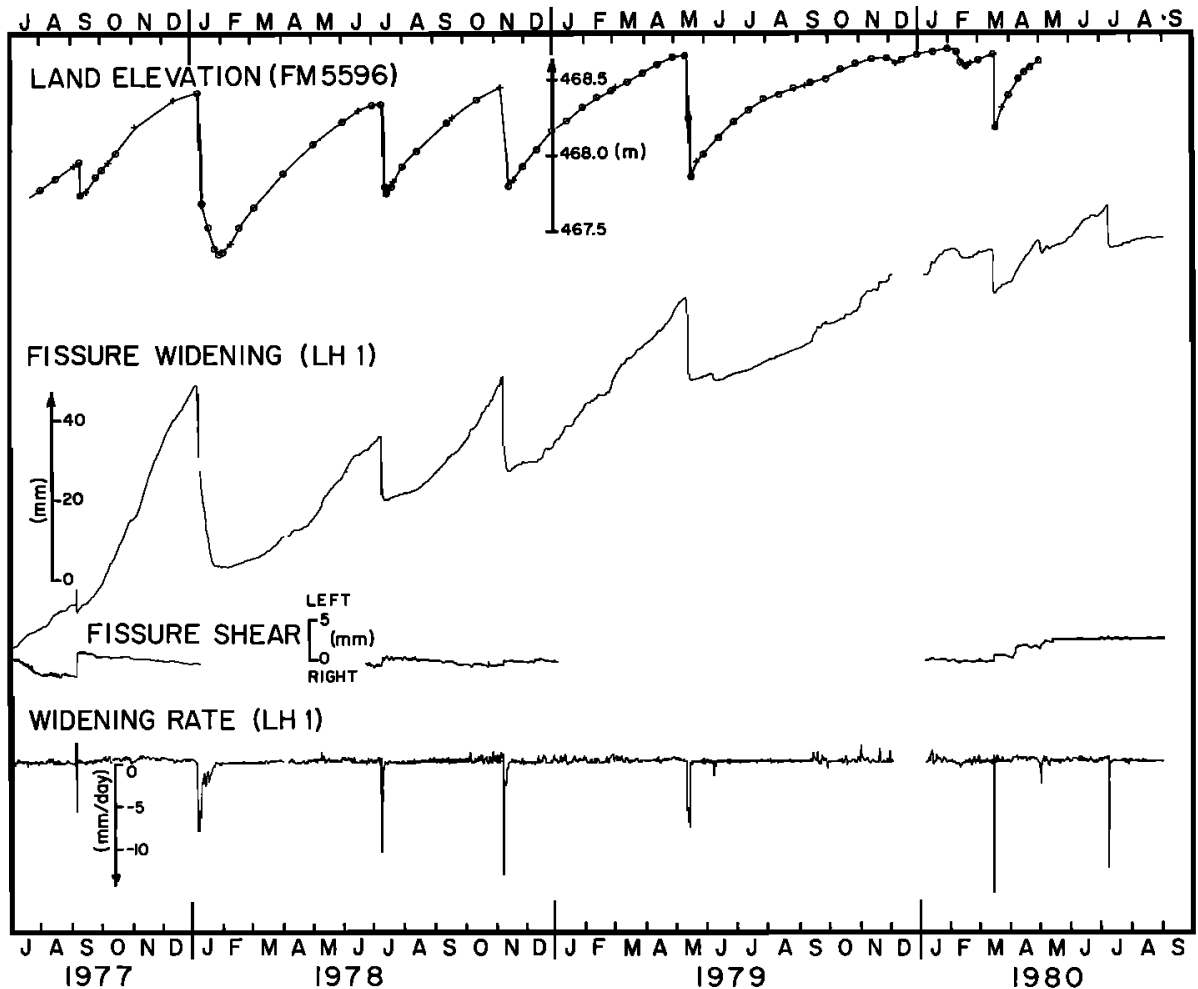

Fig. 4. Time series of fissure width (LH1), fissure shear (LH2), and fissure widening rate measured at site LH in the Krafla caldera. Land elevation at bench mark FM5596 (see also Figure 1) is shown for comparison. The land elevation data that are referenced to a bench mark located at the southern end of Lake Myvatn were made available by A. Bjornsson (personal communication, 1980; see also Bjornsson et al. [1979] for further details).

(The land elevation data were provided by $A$. B jornsson (personal communication, 1981).) Seven inflation/deflation episodes were monitored. The fissure closes during times of ground subsidence, although it never recovers its earlier width. There is thus a cumulative increase in fissure width ( $80 \mathrm{~mm}$ in 3 years) that appears to be a uniform function of time if the episodic events are neglected. Characteristics of each episode of opening lasting on the order of months during the different periods of uplift are summarized in Table 1. Uplift is rapid at first and decays slowly. Fissure width, however, tends to increase slowly at first, reaching a maximum rate at or just before subsidence. In general, the duration of periods of uplift does not correlate with the total fissure opening. The small component of shear (see Figure 4) that is observed on LH2 both during uplift and subsidence supports the results of Bjornsson et al. [1979], who found a center of uplift approximately $1 \mathrm{~km}$ east of the fissure LH.

The displacement data from the different episodes of subsidence are shown in detail in Figure 5. The fissure closes in less than $1 \%$ of the time it takes to widen. The episodes differ

TABLE 1. Periods of Uplift and Observed Average Rate of Fissure Widening at the LHL Site

\begin{tabular}{|c|c|c|c|c|c|c|}
\hline & Period & of Uplif & & $\begin{array}{c}\text { Duration, } \\
\text { days }\end{array}$ & $\begin{array}{c}\text { Fissure } \\
\text { Widening, } \\
\text { mm }\end{array}$ & $\begin{array}{c}\text { Average } \\
\text { Rate, } \\
\mathrm{mm} / \mathrm{d}\end{array}$ \\
\hline $\begin{array}{l}\text { Jan. } \\
\text { April } \\
\text { Sept. } \\
\text { Jan. } \\
\text { July } \\
\text { Nov. } \\
\text { May } \\
\text { March }\end{array}$ & $\begin{aligned} 21, & 1977 \\
20 . & 1977 \\
9, & 1977 \\
24, & 1978 \\
13, & 1978 \\
15, & 1979 \\
18, & 1979 \\
17, & 1980\end{aligned}$ & $\begin{array}{l}\text { - April } \\
\text { - Sept. } \\
\text { - Jan. } \\
\text { - July } \\
\text { - Nov. } \\
\text { - May } \\
\text { - March } \\
\text { - Ju1y }\end{array}$ & $\begin{aligned} 29, & 1977 * \\
8, & 1977 * \\
7, & 1978 \\
10, & 1978 \\
10, & 1978 \\
13, & 1979 \\
16, & 1980 \\
10, & 1980\end{aligned}$ & $\begin{array}{c}98 \\
133 \\
120.4 \\
166.7 \\
116.6 \\
178.5 \\
302.6 \\
114.4\end{array}$ & $\begin{array}{l}25 \\
36 \\
56.7 \\
32.9 \\
31.0 \\
43.6 \\
32.7 \\
22.0\end{array}$ & $\begin{array}{l}0.25 \\
0.27 \\
0.471 \\
0.197 \\
0.265 \\
0.244 \\
0.108 \\
0.192\end{array}$ \\
\hline
\end{tabular}

*Data from Bjornsson et a1. [1979]. 


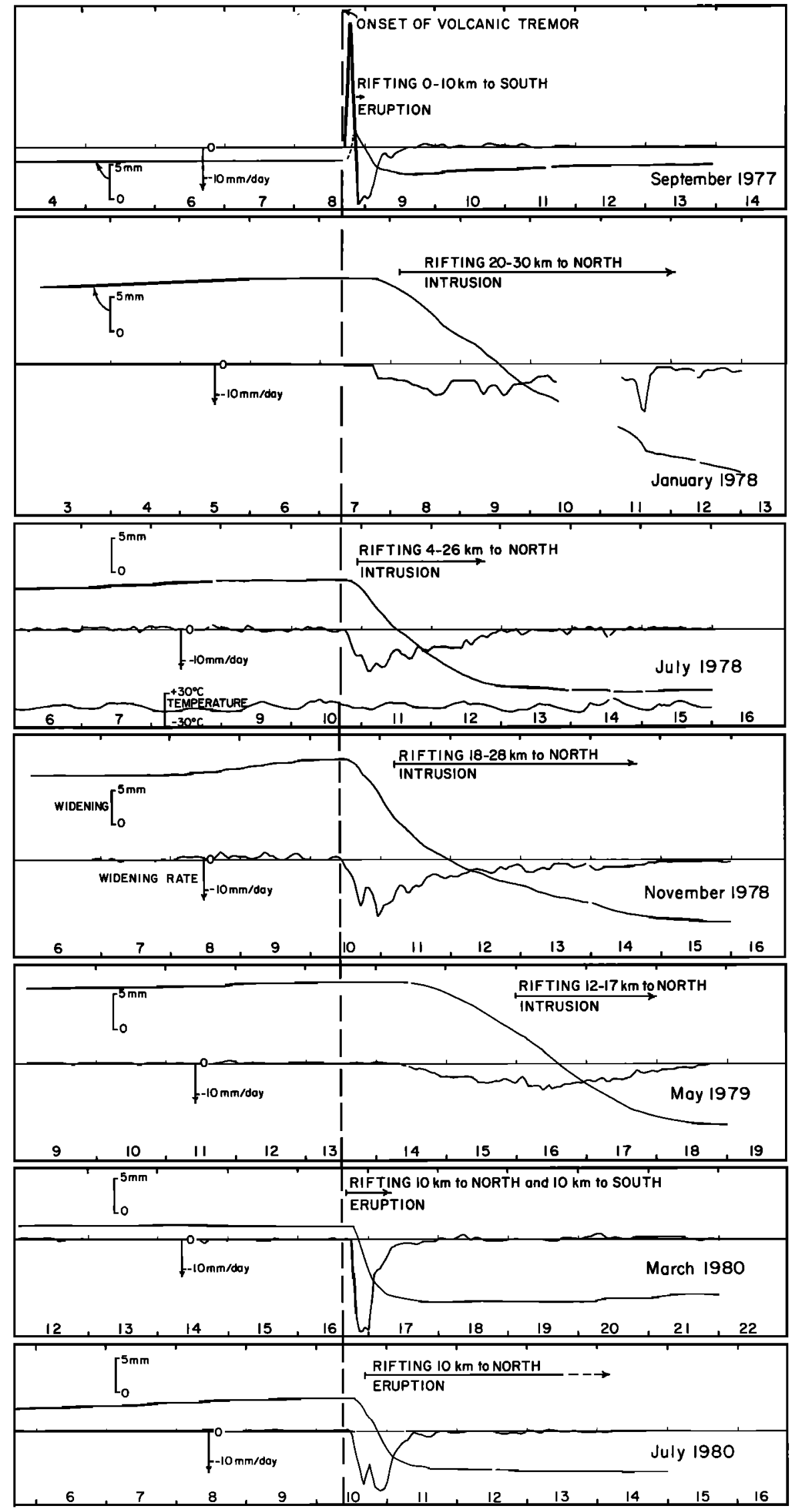

Fig. 5. The observed subsidence episodes shown in detail using data from the meter LHl. The different episodes are aligned such that the onset of volcanic tremor coincides. Data on volcanic tremor were supplied by $P$. Einarsson (personal communication, 1981). The long horizontal arrow indicates the direction and extent of rifting and accompanying notes indicate whether the subsidence was associated with an intrusion or an eruption [Tryggvason, 1980]. The rapid fluctuations in closure rate are real and can be compared to the atmospheric temperature trace in July 1978 . 
TABLE 2. Episodes of Subsidence and Observed Characteristics of Fissure closure at the LHl Site

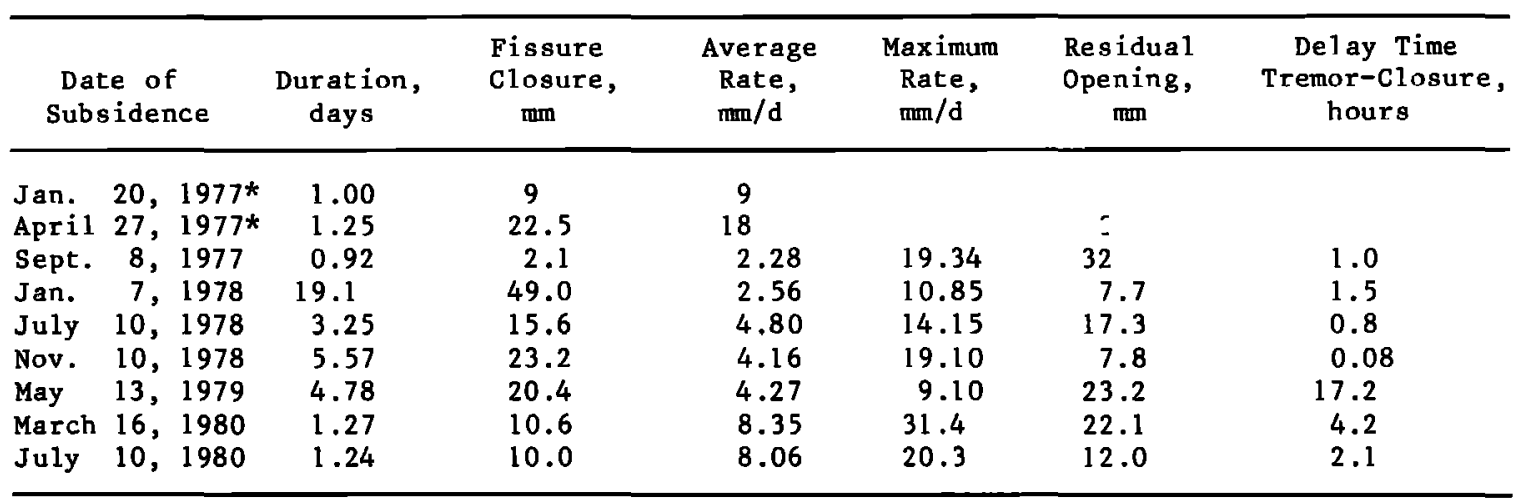

*Data from Bjornsson et al. [1979].

significantly with respect to duration and the general shape of the displacement curve. In general, the larger subsidence events have longer duration than the smaller ones. The ones with the highest peak velocity are associated with a short duration and above average residual opening (defined as the closure during subsidence subtracted from the preceding opening). The displacement data as summarized in Table 2 describe the subsidence events in terms of duration, total fissure closure, average and peak closure rate, residual opening, and a delay time from the initiation of volcanic tremor to the initiation of fissure closure. (Data on volcanic tremors were provided by P. Einarsson (personal communication, 1981).) The duration and the total fissure closure appear to be correlated such that either one can be used to describe the size of the episode. The average and the peak rates of fissure closure are generally higher for the episodes that are associated with an eruption than for episodes that are only associated with an intrusion. It is, however, less clear how the residual opening and the delay time from the onset of the volcanic tremor are related to other variables. They may reflect inertial terms that are associated with the healing and the rupture of the chamber, respectively. For the episode of July 1978 a continuous record of the atmospheric temperature is included in Figure 5 to demonstrate, in particular, that the short-period fluctuations in the rate of widening are not temperature related.

\section{Fissures in the Rift}

The three clusters of displacement meters (RA, GV, and KG) located in the rift zone were deployed to monitor the growth of fissures in the rift zone to the south of the caldera. Only two of the seven episodes migrated south. The fissures in the rift showed no clear secular or gradual steady state, long-term widening as was observed in the caldera during periods of uplift (compare Figures 4 and 6). During the two subsidence episodes of September 8, 1977, and March 16, 1980, when the magma intruded toward the south, the fissures in the rift zone widened significantly (see Figure 6). The data from the array of displacement meters can be used to determine the migration velocity of the fissure opening and the opening rate of particular fissures. Further, the data suggest a different character of fissure growth or reactivation for the two different intrusions. Several events can be seen in the data from the KA4 displacement meter. The events of November 1979 occur at the time of minor elevation changes in the caldera, but the others such as the bump in early 1979 may be a spurious signal since they are not seen on other instruments.

Several minor subsidence events that are an order of magnitude smaller than the main events have been observed at Krafla since early 1976. One such event occurred during February 10-20, 1982 , and resulted in an intrusion that migrated toward the south. The closing of LHl was $2.3 \mathrm{~mm}$ over a period of 9.5 days. Although a substantial earthquake swarm was recorded between the $\mathrm{LH}$ and $\mathrm{GV}$ clusters ( $P$. Einarsson, personal communication, 1982), no significant offsets are observed on the KA or GV displacement meters.

Episode of September 1977. The detailed data from the episode of September 1977 are shown in Figure 7. During this episode, the average velocity of migration of $f$ issure movements along the rift was $0.58 \mathrm{~m} / \mathrm{s}$. A fissure eruption commenced at 1800 hours approximately $4 \mathrm{~km}$ north of the LH site. Simultaneously the LH caldera fissure opened. In subsequent episodes when magma is known to have intruded northward this fissure invariably closed. The southward intrusion of magma as indicated by the migration of seismicity took more than 2 hours to travel to the KA cluster of displacement meters $7.3 \mathrm{~km}$ to the south of LH. The deformation can be separated into three different phases: A, B, and $C$ as shown in Figure 7 and Table 3. The $A$ phase, during which the opening of fissures begins, precedes the onset of seismicity (shown as vertical arrows in Figure 7 ) at the $\mathrm{KA}$ and GV clusters by 2 hours and 1 hour, respectively. During B phase, most of the deformation takes place, and the earthquake activity peaked. The $C$ phase signals the termination of the main deformation and shows a small overshoot and a prolonged relaxation phase.

Episode of March 1980 . This episode occurred at a slower rate than the one of September 1977 and resulted in a shorter and possibly thinner 


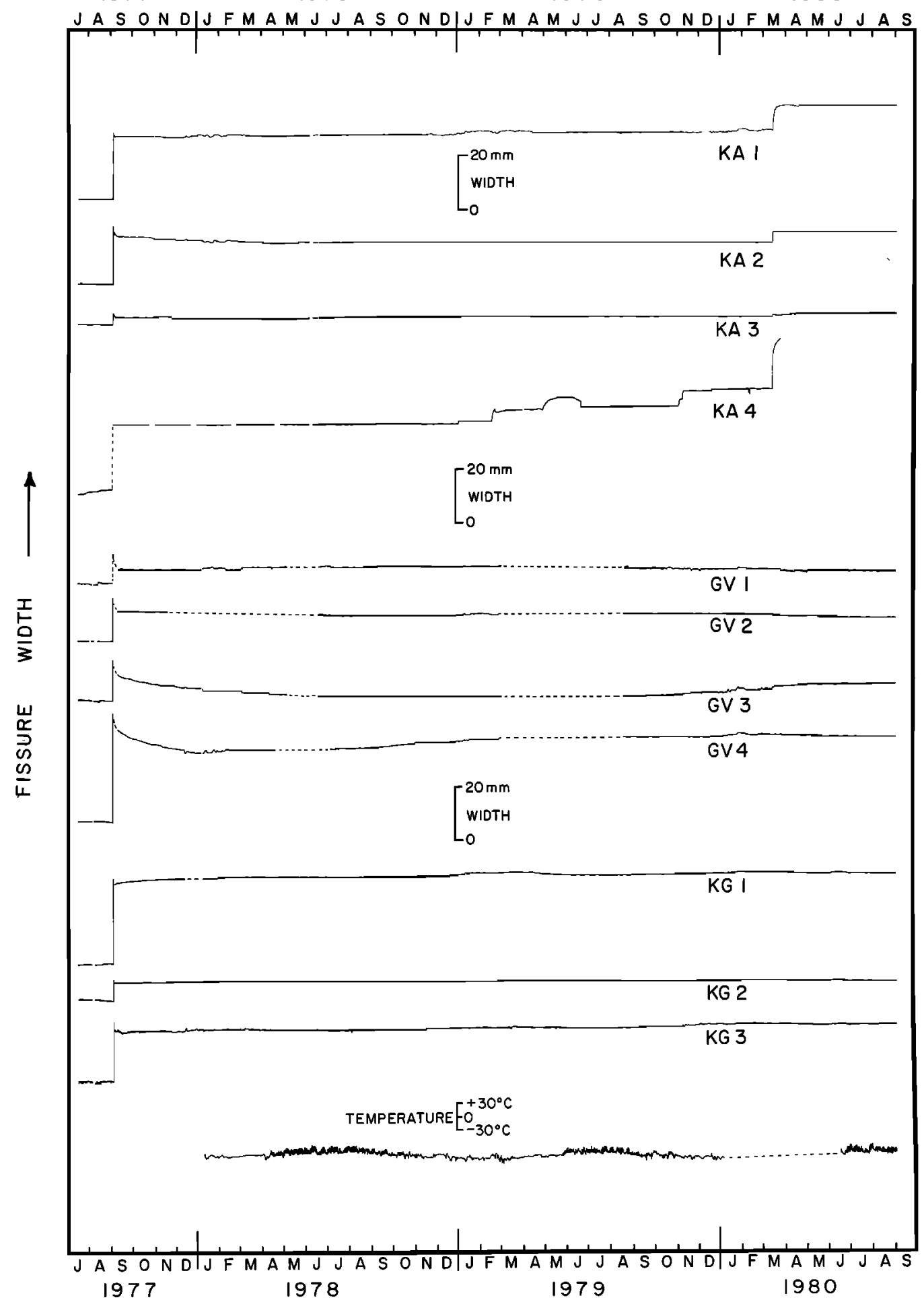

Fig. 6. Displacement meter data collected at the clusters KA, GV, and KG. Note the September 1977 and March 1980 migration events. Dashed lines indicate gaps in the data. The bottom trace is atmospheric temperature recorded at site KG.

dike intrusion. An average velocity of migration of $0.48 \mathrm{~m} / \mathrm{s}$ is determined using data from the $\mathrm{LH}$ and KG clusters (see Figure 8 and Table 3). An initiation phase ( $A$ in Figure 8 ) that can be seen clearly on LHl and the KA meters is followed by a main deformation phase $B$ that coincides with a peak in seismicity. This main phase is clearly defined by the sudden destruction of the LH4 meter. The termination or relaxation phase $\mathrm{C}$ is characterized by an exponential decay in the rate of fissure opening. This is different from the termination phase of the september 1977 episode that shows a significant overshoot and a subsequent exponentially decaying closure. This 


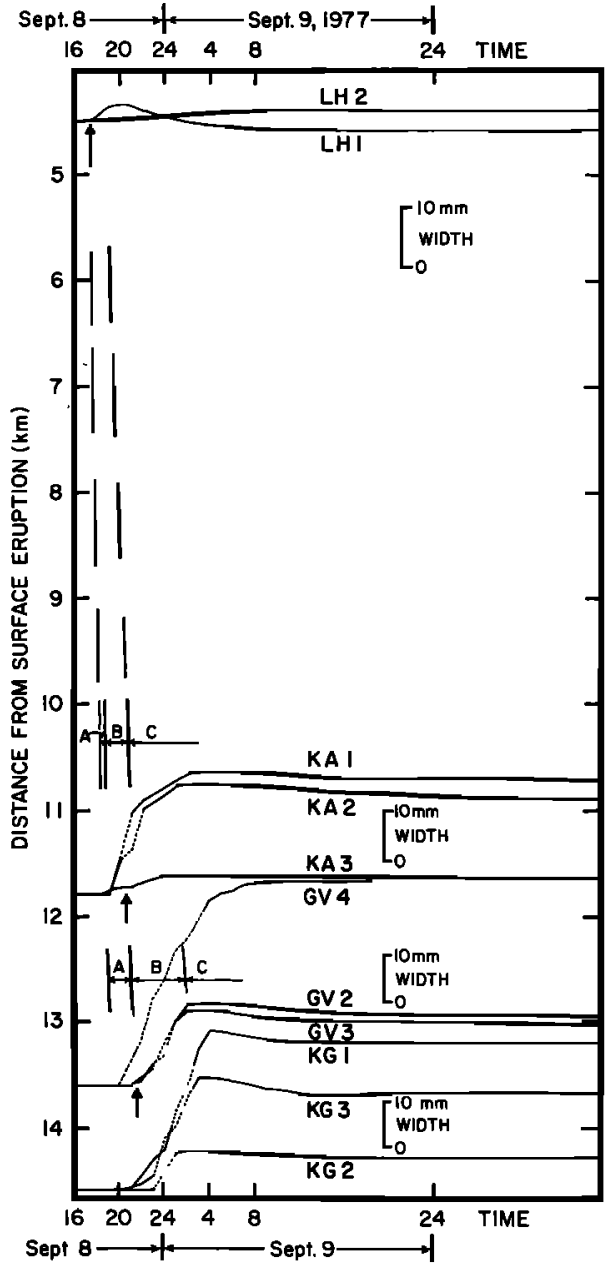

Fig. 7. The displacement meter data from the September 1977 event shown in detail. Vertically the distance from the surface eruption located north of Leirhnjukur is plotted. Three phases ( $A, B$, and $C$ ) of fissure growth can be identified. The vertical arrows indicate the onset of seismicity [Brandsdottir and Einarsson, 1979].

difference in fissure movement may be related to the depth, thickness, or velocity of dike intrusion.

\section{Interpretation}

The data on fissure growth that are presented in this report generally correlate well with other geophysical data that have been collected in the Krafla region during the same time period
[Bjornsson et a1., 1979; Hauksson, 1981]. The data also support the interpretation of Brandsdottir and Einarsson [1979], Bjornsson et a1. [1979], and Tryggvason [1980] that crusta] deformation in the region is associated with subterranean movements of magma. To unravel the details of the processes that cause extensive growth of open fissures in the Krafla region, the displacement meter data can be compared with theoretical and experimental results of fracture mechanics. The ultimate goal of this comparison is to improve the understanding of the mechanisms of rifting and associated volcanism.

\section{Swelling of the Caldera Floor}

The observed changes in the opening of the fissure LH within the caldera can be interpreted in terms of a mechanical interaction between a magma chamber at depth and the earth's surface. Presuming that the fissure $\mathrm{LH}$ is an existing crack, the form of the fissure-widening curve shown in Figure 4 is influenced by variables such as the shape or size and depth of the chamber, the rate of magma inflow or outflow, and the tensile strength of the wall rock of the chamber. It is not possible to tell if the fissure LH is an existing crack that simply opens and closes or whether it is being extended through intact rock. An existing fissure, however, appears to be a more likely case, since changes in the fissure's width correlate well with the uplift of the caldera floor and in late 1975 the floor was significantly higher than during 1976 and 1977 [Bjornsson et a1., 1979].

Mogi [1958] modeled magma chambers as simple spherical sources with excess hydrostatic pressure embedded in an elastic half space. Using leveling or triangulation data, he estimated the depth to the center of the sphere for several different Japanese volcanoes. Bjornsson et a1. [1979] and Tryggvason [1980] found that a magma chamber located at $3.0-\mathrm{km}$ depth was consistent with the leveling data from Krafla. To determine other properties of the system such as the magma pressure, the volume of the chamber, and the mechanisms of failure of the chamber walls, more sophisticated models are needed.

In an attempt to explain the repeated eruption of volcanoes such as Krafla, Blake [1981] determined a relation between the increase in magma volume and the magma compressibility within the chamber necessary to cause an eruption, presuming a steady inflow from depth and chamber walls of finite strength. When the yield strength of the walls is exceeded by the magma pressure (a function of magma compressibility and

TABLE 3. Characteristics of Episodes of Magma Migrations to the South

\begin{tabular}{|c|c|c|c|c|c|c|c|c|}
\hline \multirow[b]{2}{*}{$\begin{array}{l}\text { Date of } \\
\text { Subsidence }\end{array}$} & \multirow{2}{*}{$\begin{array}{c}\text { Migration } \\
\text { Duration } \\
\text { (A phase) } \\
\text { hours }\end{array}$} & \multirow{2}{*}{$\begin{array}{c}\text { Migration } \\
\text { Distance, } \\
\quad \text { km }\end{array}$} & \multicolumn{2}{|c|}{ Migration Velocity, $\mathrm{m} / \mathrm{s}$} & \multicolumn{4}{|c|}{ Rate of Widening, $\mathrm{nm} / \mathrm{d}$} \\
\hline & & & $\begin{array}{l}\text { Maximum } \\
\text { (A phase) }\end{array}$ & $\begin{array}{l}\text { Average } \\
\text { (B phase) }\end{array}$ & KAl & KA2 & KA3 & KA4 \\
\hline $\begin{array}{l}\text { Sept, } 8,1977 \\
\text { March 16, } 1980\end{array}$ & $\begin{array}{l}3.0 \\
3.5\end{array}$ & $\begin{array}{r}10.1 \\
7.3\end{array}$ & $\begin{array}{l}0.95 \\
0.58\end{array}$ & $\begin{array}{l}0.58 \\
0.48\end{array}$ & $\begin{array}{l}>190 \\
\quad 10.3\end{array}$ & $\begin{array}{r}>110 \\
12.0\end{array}$ & $\begin{array}{r}15.3 \\
2.6\end{array}$ & 49.1 \\
\hline
\end{tabular}




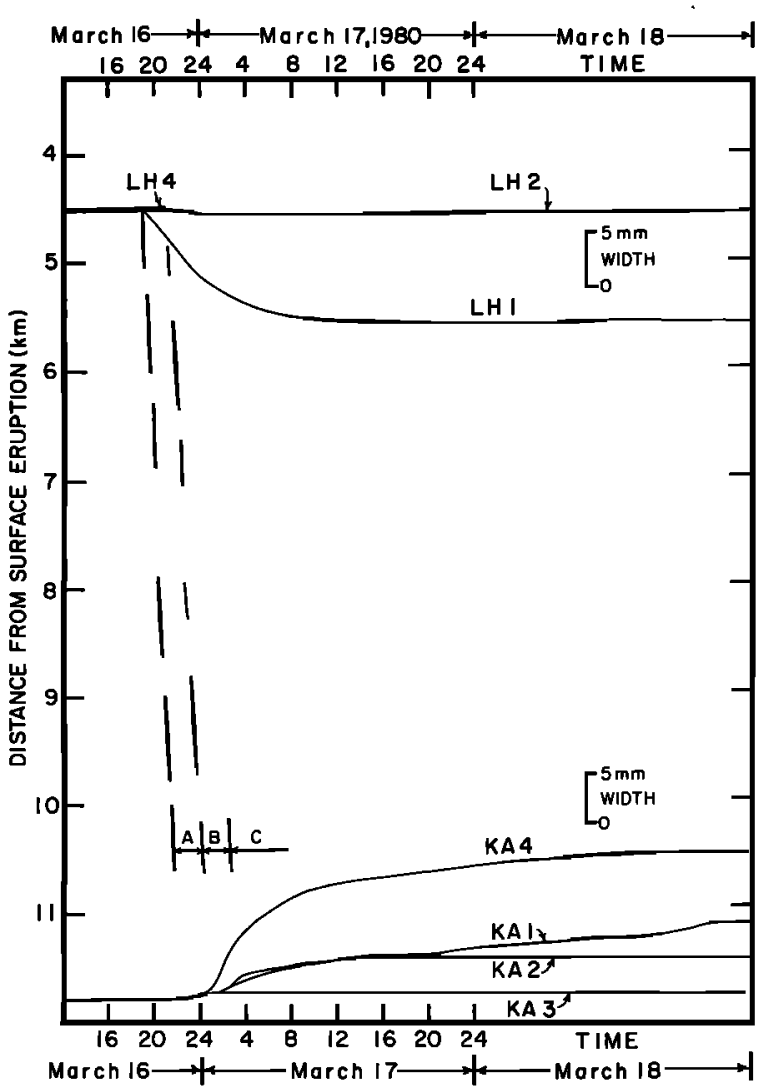

Fig. 8. The displacement meter data from the March 1980 event shown in detail. Vertically the distance from the surfce eruption located north of Leirhnjukur is plotted. Three phases (A, B, and $C$ ) of fissure growth can be identified.

possible volume expansion of the chamber), an eruption or an intrusion will take place. Blake's model, when applied to the Krafla data, predicts that most of the uplift periods should have similar time durations and that the subsidence episodes should be of similar magnitude and intensity.

In Figure 9 the total fissure opening measured during each period of uplift is plotted as a function of the respective duration of uplift. The durations of uplift cluster between 100 and 180 days, as would be expected from Blake's model. The total openings, however, scatter from 21 to $57 \mathrm{~mm}$. These variations in the fissure opening can be interpreted as substantial fluctuations in the rate of magma inflow which is presumed to be constant in Blake's model. Previously, Bjornsson et al. [1979] and Tryggvason [1980] suggested that changes in regional elevation in the Krafla caldera were proportional to the rate of magma inflow. The data from LH1 thus indicate that the time interval between subsidence episodes is independent of the opening rate or the excess magma pressure and probably is influenced by a time-dependent failure process. Time-dependent failure of the chamber walls would require processes such as static fatigue [Lawn and Wilshaw, 1975] or stress corrosion [Anderson and Grew, 1977] to affect the yield strength of the wall rock. Neither this interpretation nor the
Blake's model include the possible effects of regiona1, tensile stress fields that in the case of Krafla strike approximately east-west and may be time dependent. Such a stress field at Krafla that can be associated with the spreading of the North American and Eurasian plates would be relieved gradually in successive intrusion episodes, and as a result, the time interval between subsidence episodes should increase. The data presented here, however, do not cover a sufficiently long time period to examine whether such a trend exists.

The fissure width at $\mathrm{LH}$ in Figure 4 shows a highly repeatable pattern of opening and closing episodes. One way of describing this repeatability is to plot the total fissure closure within the caldera, as observed during each subsidence episode as a function of the opening rate during the previous uplift period (see Figure 10). The best fit line to the data has a correlation coefficient of 0.96 (if the subsidence of September 1977 is neglected). This line suggests that the faster the opening rate during uplift, the larger the following subsidence episode will be. Blake's model requires the magma pressure to exceed the lithostatic pressure in addition to the tensile strength of the walls for an eruption to take place. The presence of time-dependent mechanisms of failure alternatively indicates that the magma pressure does not have to exceed the tensile strength of the walls. Once the velocity of crack growth reaches a critical value, a catastrophic failure of the walls takes place,

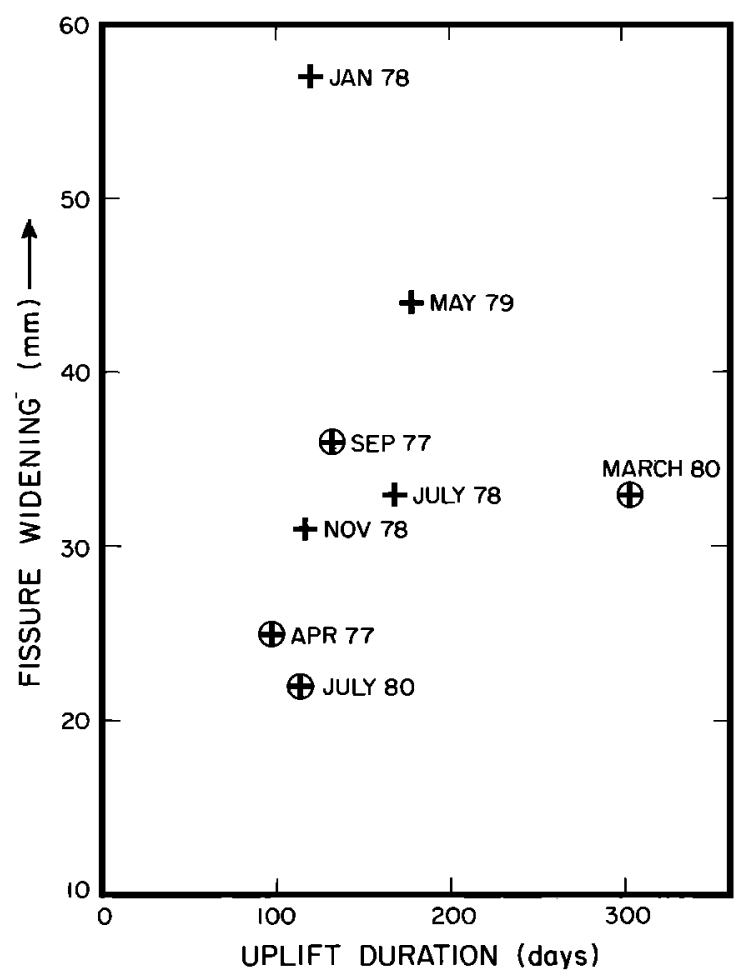

Fig. 9. Width of the fissure LH during periods of uplift plotted against the respective upl ift duration. The crosses are associated with intrusive events, and the circled crosses are associated with eruptions. 


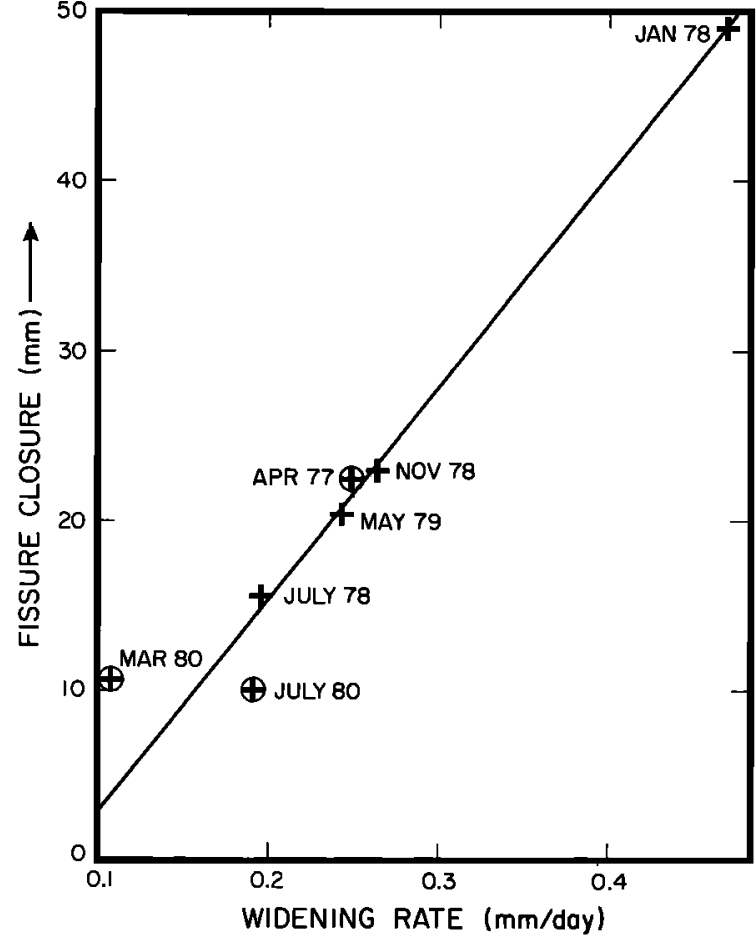

Fig. 10. Closure of the fissure LH during episodes of subsidence shown as a function of widening rate during previous uplift period. The straight $l$ ine is a 1 inear best fit to the data.

and the magnitude of subsidence is determined by the available excess magma pressure in the chamber.

\section{Fissuring of the Rift Floor}

The observed growth of fissures in the rift zone can be interpreted as the mechanical interaction between a magma-filled crack or dike at depth and the earth's surface. To explain the extensive growth of open fissures and normal faulting that was observed during the episodes of September 1977 and March 1980, it is necessary to assume that many sma11 dikes were intruded at shallow depths (1ess than $1 \mathrm{~km}$ ) in addition to the main central dike (see Figure 11). The displacement meter data can be used to study in detail the formation of these small dikes that represent secondary features of the rupturing of the $p$ late boundary. The discussion below focuses on the subsidence episode of September 1977 since it is much better documented than the episode of March 1980 .

One possible scenario that explains the surface deformation observed in September 1977 postulates the intrusion of a main dike at depth, as shown in Figure 11. This main dike initiates the formation of the 1-2 km wide graben, as reported by Bjornsson et al. [1979]. During the emplacement of the dike the surrounding host rock is cracked and faulted such that small volumes of magma can migrate close to the surface. One such prospective dikelet $r$ an into a borehole in the geothermal field at Namafjall and resulted in a volcanic eruption of flares and glowing scoria through the borehole [Larsen et al., 1979].

To estimate the depth $d$ to the center of a dike and its width $\Delta x$ at depth, Pollard and Holzhausen [1979] presented a theoretical relationship between $\Delta v / \Delta x$ and $d / a$ where $2 a$ is the dike height and $\Delta v$ is the observed horizontal displacement at the surface. On the basis of seismicity data, Brandsdottir and Einarsson [1979] suggested that the depth to the bottom of the main dike was approximately 4 kn below the $K A, G V$, and KG clusters of displacement meters. The length of the dike is approximately $10 \mathrm{~km}$. Using geodetic data taken within the caldera, Tryggvason [1980] estimated that $1.6 \times 10^{7} \mathrm{~m}^{3}$ of magma was injected into the dike and his geodetic data in the rift zone show a total widening of the rift of approximately $1 \mathrm{~m}$. When assuming that the dike is $3 \mathrm{~km}$ high, $10 \mathrm{~km}$ long, and $1 \mathrm{~m}$ wide, and rectangular in shape, its volume is equal to $3 \times 10^{7} \mathrm{~m}^{3}$, which is fairly close to Tryggvason's [1980] estimate. The relation beteen $\Delta v / \Delta x$ and $d / a$ proposed by Pollard and Holzhausen [1979] predicts that a dike of this size and at this depth would at most result in $0.3 \mathrm{~m}$ of displacement or fissure opening at the earth's surface. Therefore, a main dike at least $3 \mathrm{~m}$ wide at depth or alternately several smaller dikes at shallow depths are needed to account for the total horizontal displacement of $1 \mathrm{~m}$. If the main dike is injected closer than $1 \mathrm{~km}$ to the surface, the total graben width $W$ (as shown in Figure 1l) would become smaller than observed [Pollard and Holzhausen, 1979].

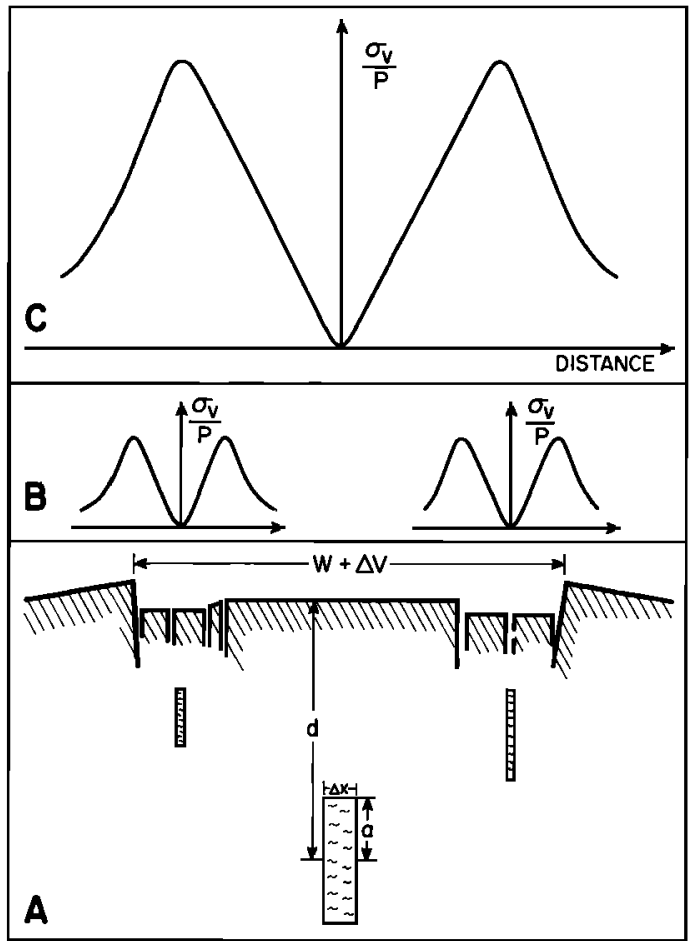

Fig. 11. (a) A schematic cross section of the rift zone and possible dike intrusions.

Normal stresses related to the shallow dikes acting parallel to the free surface; $P$ is the pressure within the dike. (c) Normal stresses associated with the main dike at depth; stress is shown as a function of distance away from the center of the dike along the free surface [Po1lard and Holzhausen, 1979]. 
Figure 11 shows a schematic cross section of the main graben and the dike at depth. In addition, two small dikes or dikelets are shown close to the extensive surface breakage, which is subparallel to the main boundary faults of the graben. Schematic plots of the horizontal tensile stress $\sigma_{v}$, as estimated by Pollard and Holzhausen [1979], are shown for both the main dike (Figure $11 \mathrm{c}$ ) and the two dikelets (Figure 11b) as a function of distance away from the dikes. It is clear that a superposition of both types of stress fields is needed to explain the observed surface displacement. In the September 1977 episode, displacement meters KA4 and KG1 that are probably located on the boundary faults farthest west and east, respectively, show the largest total displacement (see Figure 6). The other displacement meters monitor the formation of small fissures within the main graben. For example, the total displacement measured by the $\mathrm{KA}$ cluster was at least $0.2 \mathrm{~m}$, and the graben width is approximately $150 \mathrm{~m}$. This deformation can be explained by a 0.6 -m-wide dike at depth from $100 \mathrm{~m}$ down to $500 \mathrm{~m}$ or alternatively, by a 2-m-wide dike at depth from 200 to $400 \mathrm{~m}$.

The fissure movements during the March 1980 episode that were smaller in magnitude and occurred at a slower rate than in September may possibly be explained by a thinner central dike or the absence of shallow dikelets during that episode.

The model of Pollard and Holzhauzen [1979] assumes linear, elastic material properties and gives reasonably qualitative estimates of the distribution of deformation and how the deformation can be expected to decay with distance away from the center of the dike. To account for the extensive fissuring and normal faulting in a quantative way, a more sophisticated model is needed. Such a model would have to satisfy both the displacement meter data and seismic data such as focal mechanisms and stress drops as well as the long-term geodetic data. Some aspects of rifting such as the finite duration time of the fissuring or the local viscoelastic slumping and readjustment of crustal blocks, that depend on local conditions and vary from one event to the next, however, may prove difficult to model.

\section{Discussion}

Subterranean magma chambers at shallow crustal levels and dike intrusions can influence the state of stress in the Icelandic crust. These contributions, of both elastic and thermal stresses, are superimposed on the regional tectonic stress field that controls the movements of the lithospheric plates. Although the current activity at Krafla volcano follows a 240-year-long period of quiescence it is not possible to tell uniquely if the sequence of events is dominated by regional tension or magma fracturing. Haimson and Rumme1 [1982], who present results of hydrofracturing stress measurements from Iceland, point out that measurements $t$ aken west of the rift zone indicate that the plates are being pushed apart. One measurement east of the rift zone, however, indicates that the plates are being pulled apart. The geodetic data that are collected in northeastern Iceland by Moller and Ritter [1980] demonstrate that extension is occurring within the rift zone and compression in the flanks as a result of the current activity. The seismic data [Brandsdottir and Einarsson, 1979] and the displacement meter data support the idea that the rift zone is in a state of approximately east-west horizontal tension. The strain release along the plate boundary appears to be episodic. All of the observed events of strain release have begun within the Krafla caldera and have resulted in a horizontal dike injection along the plate boundary.

One of the major results of this work is that the velocity of crack growth is several orders of magnitude less than the shear wave velocity of the respective basaltic lava pile. Therefore, no significant seismic energy can be radiated as a result of the growth. Further, the fissure growth appears to be an almost continuous process that lasts for several hours rather than discontinuous process. Hence, it seems unlikely that the fissure growth constitutes the exclusive source of volcanic tremors as suggested by Aki et a1. [1977] and Anderson [1978]. It is still possible, however, that the flow of magma which can be either laminar or turbulent contributes significantly to the generation of volcanic tremors. Alternatively, if a model such as that presented by Hill [1977] of tension cracks connected by strike slip or dip slip faults applies, it is possible that earthquakes and volcanic tremors are related to motion on the strike or dip slip faults rather than to the opening of the tension cracks.

\section{Conclusions}

Studies of the growth of large ground fissures during rifting of the p1ate boundary in north Iceland lead to the following conclusions.

Continuous growth of fissures is observed in the floor of the Krafla caldera during periods of land uplift. The average rate of widening varies from one period to another ranging from 0.1 to $0.5 \mathrm{~mm} / \mathrm{d}$. During rapid episodes of subsidence the fissure closing rates range from 2.3 to 18 $\mathrm{mm} / \mathrm{d}$.

During the two subterranean episodes of magma intrusion of September 1977 and March 1980 the magma migrated toward the south with an average velocity of 0.6 and $0.5 \mathrm{~m} / \mathrm{s}$, respectively. Some fissures widened with a rate greater than 190 $\mathrm{mm} / \mathrm{d}$ in the September 1977 episode. During periods of uplift the fissures in the rift zone outside the caldera are inactive, and their opening is almost unchanged.

The displacement meter data indicate that the time interval between subsidence episodes is independent of the fissure-opening rate or the excess magma pressure and could be influenced by a time-dependent failure process. The magnitude of a subsidence event appears to be determined by the available excess magma pressure in the chamber.

Acknowledgments. The author wishes to thank Roger Bilham, Lucile M. Jones, and Terry Engelder for critically reviewing the manuscript. Pall Einarsson, Bryndis Brandsdottir, Axel Bjornsson, and Robert 0 . Burford provided helpful comments. 
John Beavan made his computer programs available for processing the data. Axe1 Bjornsson of the National Energy Authority of Iceland kindly made the land elevation data available and provided logistics support in Iceland. Hjortur Tryggvason, also at the National Energy Authority, took care of the displacement meters in my absence and helped me with the annual maintenance. This work benefited from the U.S. Geological Survey contract 14-08-0001-19747 and NASA contract NGR-146. Gianine Lupo-Brown digitized most of the strip charts and her efforts are greatly appreciated. The figures were drafted by Patricia Catanzaro and Kazuko Nagao. Lynn Niebour typed the manuscript. Lamont-Doherty Geological Observatory Contribution 3403 .

\section{References}

Aki, K., M. Fehler, and S. Das, Source mechanism of volcanic tremor: Fluid-driven crack models and their application to the 1963 Kilauea eruption, J. Volcanol. Geotherm. Res., 2, $259-287,1977$.

Anderson, 0 . L., The role of magma vapors in volcanic tremors and rapid eruptions, Bull. Volcano1., 41-4, 341-353, 1978

Anderson, 0. L., and P. C. Grew, Stress corrosion theory of crack propagation with applications to geophysics, Rev. Geophys. Space Phys., 15, 77-104, 1977.

Bjornsson, A., G. Johnsen, S. Sigurdsson, G. Thorbergsson, and E. Tryggvason, Rifting of the plate boundary in north Iceland, 1975-1978, J. Geophys. Res., 84, 3029-3038, 1979.

Blake, S., Volcanism and the dynamics of open magma chambers, Nature, 289, 783-785, 1981.

Brandsdottir, B., and P. Einarsson, Seismic activity associated with the September 1977 deflation of the Rrafla central volcano in NE Iceland, J. Volcanol. Geotherm. Res., 6 , $197-212,1979$.

Burford, R. 0., R. D. Nason, and P. W. Harsh, Studies of fault creep in central California, Earthquake Inf. Bull. U.S. Geol. Surv., 10, 174-181, 1978 .

Duffield, W. A., and R. O. Burford, An accurate invar-wire extensometer, J. Res. U.s. Geol. Surv., 1, 569-577, 1973.

Haimson, B. C., and F. Rumme 1, Hydrofracturing stress measurements in the IRDP drill hole at Reydarf jordur, Iceland, J. Geophys. Res., 87, $6631-6649,1982$
Hauksson, E., Episodic rifting and volcanism at Krafla in north Iceland: Radon (222) emission from fumaroles near Leirhnjukur, J. Geophys. Res., 86, 11806-11804, 1981 .

Hill, D. P., A model for earthquake swarms, J. Geophys. Res., 82, 1347-1352, 1977.

Larsen, G., R. Gronvold, and $S$. Thorarinsson, Volcanic eruption through a geothermal borehole at Namafja11, Iceland, Nature, 278, 707-710, 1979 .

Lawn, B. R., and T. R. Wilshaw, Fracture of Brittle Solids, Cambridge University Press, New York, 1975

Mogi, K., Relations between the eruptions of various volcanoes and the deformation of the ground surfaces around them, Bull. Earthquake Res. Inst., Tokyo Univ., 36, 99-134, 1958.

Moller, D., and B. Ritter, Geodetic measurements and horizontal crustal movements in the rift zone of NE-Iceland, J. Geophys., 47, 110-119, 1980 .

Nakamura, K., En echelon features of Icelandic ground fissures, Acta Nat. Is1., 2(8), 3-15, 1970.

Pelzer, H., and C. Gerstenecker, Measurements of distance and tilt changes in fissures of northern Iceland, J. Geophys., 47, 166-170, 1980 .

Pollard, D. D., and G. Holzhausen, On the mechanical interaction between a fluid-filled fracture and the earth's surface, Tectonophysics, 53, 27-57, 1979.

Saemundsson, $K_{.}$, Geologic map of Iceland, sheet 7, NE-Iceland, Iceland Geod. Surv. and Museum of Nat. Hist., Reykjavik, Iceland, 1977.

Saemundsson, K., Fissure swarms and central volcanoes of the neovolcanic zones of Iceland, Geol. J. Spec. Issue, 10, 415-432, 1978.

sigurdsson, $0 .$, Surface deformation of the Kraf1a fissure swarm in two rifting events, $J$. Geophye., 47, 154-159, 1980 .

Tomasson, H., The opening of tectonic fractures at the Langalda dam, in Des Grands Barrages, Douzienme Congrea Proceedings, Mexico, Pp. 75-91, Commission Internationale, des Grands Barrages, Mexico, 1976.

Tryggvason, E., Subsidence events in the Krafla area, north Iceland, 1975-1979, J. Geophys.. 47, 141-153, 1980 .

(Received May 14, 1982;

revised August 27,1982 ; accepted October 22, 1982.) 